University of Nebraska - Lincoln

DigitalCommons@University of Nebraska - Lincoln

Nebraska Cooperative Fish \& Wildlife Research Nebraska Cooperative Fish \& Wildlife Research Unit -- Staff Publications

2001

\title{
Assessment of Outputs from Smith-Root Model-5.0 GPP and Model-7.5 GPP Electrofishers
}

\author{
Kevin L. Pope \\ Texas Tech University, kpope2@unl.edu \\ Brian E. Van Zee \\ Texas Parks and Wildlife Department \\ Michael C. Mayo \\ Texas Tech University \\ Mohammed Rahman \\ Texas Tech University
}

Follow this and additional works at: https://digitalcommons.unl.edu/ncfwrustaff

Part of the Other Environmental Sciences Commons

Pope, Kevin L.; Van Zee, Brian E.; Mayo, Michael C.; and Rahman, Mohammed, "Assessment of Outputs from Smith-Root Model-5.0 GPP and Model-7.5 GPP Electrofishers" (2001). Nebraska Cooperative Fish \& Wildlife Research Unit -- Staff Publications. 70.

https://digitalcommons.unl.edu/ncfwrustaff/70

This Article is brought to you for free and open access by the Nebraska Cooperative Fish \& Wildlife Research Unit at DigitalCommons@University of Nebraska - Lincoln. It has been accepted for inclusion in Nebraska Cooperative Fish \& Wildlife Research Unit -- Staff Publications by an authorized administrator of DigitalCommons@University of Nebraska - Lincoln. 
North American Journal of Fisheries Management 21:353-357, 2001

(C) Copyright by the American Fisheries Society 2001

\title{
Assessment of Outputs from Smith-Root Model-5.0 GPP and Model-7.5 GPP Electrofishers
}

\author{
KeVIN L. PoPE* \\ Department of Range, Wildlife, and Fisheries Management, \\ Texas Tech University, Lubbock, Texas 79409, USA \\ BRIAN E. VAN ZEE \\ Texas Parks and Wildlife Department, Inland Fisheries Division, \\ Post Office Box 835, Canyon, Texas 79015, USA \\ Michael C. Mayo and Mohammed Rahman \\ Department of Electrical Engineering, Texas Tech University, Lubbock, Texas 79409, USA
}

\begin{abstract}
We evaluated the outputs from eight Smith-Root electrofishers (two factory-rigged model-5.0 GPP boats, four biologist-rigged model-5.0 GPP boats, and two biologist-rigged model7.5 GPP boats), using an oscilloscope to determine the actual waveforms (voltage as a function of time), current, and power produced for various settings. Differences were found in average power outputs among the six model-5.0 GPP electrofishing boats. In terms of average power output, biologist-rigged electrofishing boats using generators and control boxes purchased from Smith-Root were as or more effective than those rigged by Smith-Root. However, factory-rigged boats generally contained additional safety features that should be considered when purchasing electrofishing equipment. Outputs were similar between the two model-7.5 GPP boats. We were unable, with information obtained solely from the control boxes, to calculate power output produced by the Smith-Root electrofishers. Thus, additional meters (e.g., a voltage meter capable of measuring true root mean square) would be needed to determine power output in the field. An increase in resistance (simulating a decrease in water conductivity) resulted in a decrease in average power and current and a slight increase in voltage.
\end{abstract}

Fisheries biologists have long recognized the need for standardized sampling schemes to compare sampling data among years within a water body and among water bodies within a given year (Willis and Murphy 1996). Standardized sampling involves repeated use of the same effective gears and techniques at effective times in fixed locations (Willis and Murphy 1996). The intent is to control for gear, season, and location biases associated with sampling so that real changes in fish populations are detected.

An understanding of sampling gears, including electrofishers, is needed to properly assess fishery data. For example, electrofishing boats may break down, causing biologists to use different equipment than was used for previous sampling. If differences in efficiency exist between electrofishing gears, then comparisons between catch rate and possibly size structure estimates obtained by the two different gears would not be appropriate. Thus, an understanding of variability among dif-

* Corresponding author: kevin.pope@ttu.edu

Received November 12, 1999; accepted September 10, 2000 ferent electrofishing boats is needed to maintain consistent sampling. In addition, a general understanding of electrofishing equipment is valuable in itself.

Historically, the Texas Parks and Wildlife Department (TPWD) attempted to use standardized electrofishing boats. Generators and control units of identical size and capacity (Smith-Root model5.0 GPP electrofishers), as well as foot pedals and droppers (anodes), were purchased. However, two TPWD inland fisheries districts recently began using different electrofishing equipment (SmithRoot model-7.5 GPP electrofishers) to more effectively sample high conductivity $(>4,000 \mu \mathrm{S} /$ $\mathrm{cm}$ ) waters. Furthermore, a majority of electrofishing boats used by TPWD were assembled by district crews who purchased generators and control units from Smith-Root, Inc., and boats and accessories from various vendors. Thus, differences in ages of boats and electrofishers, wiring schemes, and accessories exist within the TPWD electrofishing fleet.

Van Zee et al. (1996) described outputs produced by Coffelt VVP-15 electrofishers. They discovered that the so-called "high-output, pulsed 
AC waveform" was really a DC waveform with a narrow duty cycle. Because no such assessment has been conducted for Smith-Root electrofishers, we evaluated the outputs from eight Smith-Root GPP electrofishers by using an oscilloscope to determine the actual waveforms (voltage as a function of time), current, and power produced for various settings. Specifically, our objectives were to (1) compare the outputs (i.e., voltage, current, and power) among 5.0 GPP electrofishers on boats rigged by Smith-Root, Inc., with boats rigged by fisheries biologists; (2) compare the outputs among Smith-Root 5.0 GPP and 7.5 GPP electrofishers; and (3) determine effects of three resistance levels (simulating different levels of water conductivity) on the outputs of 5.0 GPP and 7.5 GPP electrofishers.

\section{Methods}

On 26 and 27 February 1999 we evaluated outputs from six Smith-Root model-5.0 GPP electrofishers and two Smith-Root model-7.5 GPP electrofishers. We used an oscilloscope (Fluke model 99B) to determine the actual waveforms produced as well as the voltage, current, and power for various settings. Two of six 5.0 GPP electrofishing boats were purchased from the factory, whereas the other four 5.0 GPP electrofishing boats contained Smith-Root generators, control boxes, foot pedals, and droppers installed by fisheries biologists. For each electrofishing boat, the hull served as the cathode and two booms with four droppers per boom served as the anodes.

Each electrofisher was evaluated as it is used in the field (i.e., electrical accessories were operated to simulate nighttime electrofishing). We used an oscilloscope to determine outputs of each electrofisher, one at a time, by connecting a resistor in circuit between one boom (starboard side) and the boat (out of water). We were unable to obtain manufactured resistors large enough to sustain a load on the generator; thus, we created a resistor by placing two aluminum rods $(6.35 \mathrm{~mm}$ diameter, $40.64 \mathrm{~cm}$ long) vertically into a $378-\mathrm{L}$ plastic tank containing $105 \mathrm{~L}$ of water. Half of each rod was vertically submersed in water, and distance between the rods was $61 \mathrm{~cm}$. We connected one aluminum rod to the anode and the other aluminum rod to the cathode (Figure 1). Water conductivity was monitored throughout each test with a conductivity meter (YSI model 30). Resistance was calculated with the formula, $R=l \cdot(\sigma \cdot A)^{-1}$, where $R$ is resistance $(\Omega), \sigma$ is water conductivity $(\mathrm{S} / \mathrm{cm})$, $A$ is the cross-sectional area $\left(\mathrm{cm}^{2}\right)$ of water be-

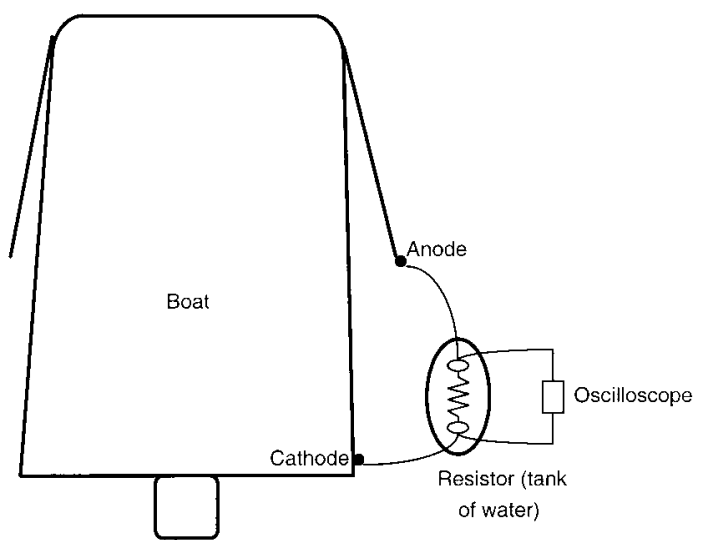

FIgURE 1.-Schematic of electrical circuit for assessment of electrical outputs produced by Smith-Root model-5.0 GPP and model-7.5 GPP electrofishing boats.

tween the aluminum rods, and $l$ is the distance $(\mathrm{cm})$ between rods. This equation is valid for a circuit that has a purely resistive load. The resistor we used had a low capacitance in the circuit. We ignored this capacitance and assumed that no element of reactive power existed in our calculations of resistance and power. Thus, our calculations of resistance and power were close approximations and not exact measurements.

The oscilloscope was used to digitize and store each of the waveforms until the electronic image could be transferred to a personal computer via a general-purpose interface bus. Average power was calculated using the formula, $P=V^{2} / R$, where $P$ is average power (W), $V$ is voltage $(\mathrm{V})$ measured with the oscilloscope as root mean square (rms) voltage, and $R$ is resistance $(\Omega)$ of the resistor. Current (rms) was calculated using the formula, $I$ $=P / V$, where $I$ is current (A).

We assessed the outputs of all eight boats (six 5.0 GPP and two 7.5 GPP electrofishers) with a resistance of 23-26 $\Omega$ (specific conductance $=$ $2,322-2,346 \mu \mathrm{S} / \mathrm{cm}$ at $25^{\circ} \mathrm{C}$ ). Because initial assessments indicated that waveforms produced by Smith-Root electrofishers were those described in the instruction manual, further assessments of these boats were conducted using only pulsed DC (60 pulses/s), the waveform used most often by TPWD biologists when electrofishing. In these tests we assessed outputs of electrofishers at 10 , $20,40,60,80$, and $100 \%$ of range on all possible levels of voltage (500 and $1,000 \mathrm{~V}$ for the 5.0 GPP; $170,340,500$, and $1,000 \mathrm{~V}$ for the $7.5 \mathrm{GPP}$ ).

We also assessed the effects of three different resistance levels (simulating different levels of wa- 
ter conductivity) on outputs produced at the $40 \%$ setting of the 500-V range by one factory 5.0 GPP boat, one 5.0 GPP boat set up by biologists, and one 7.5 GPP boat set up by biologists. We obtained a high resistance (i.e., 215-220 $\Omega$ ) by placing distilled water (specific conductance $=251-256 \mu \mathrm{S} /$ $\mathrm{cm}$ at $25^{\circ} \mathrm{C}$ ) in the tank (resistor) and a low resistance (i.e., $10 \Omega$ ) by adding salt to the water (specific conductance $=5,037-5,048 \mu \mathrm{S} / \mathrm{cm}$ at $25^{\circ} \mathrm{C}$ ).

We tested differences in average power output between 5.0 GPP electrofishers using a mixed model in which average power was a function of boat (random effect) and percent of range (fixed effect). We began with a full model (including all interactions) and removed nonsignificant interactions to obtain a final quadratic model. When significant boat effects were found in the model, a least significant difference (LSD) test was used to determine which boats differed. Statistical significance was set at $\alpha=0.05$.

\section{Results \\ Model-5.0 GPP Electrofishers}

With a resistance of 23-26 $\Omega$, the maximum average power output of 5.0 GPP electrofishing boats on low range $(500 \mathrm{~V})$ was $1,864-2,486 \mathrm{~W}$ and on high range $(1,000 \mathrm{~V})$ was $5,684-7,019 \mathrm{~W}$. Under these conditions, the boats also produced 214-242 V and 8.5-10.3 A on low range and 368$410 \mathrm{~V}$ and 15.4-17.3 A on high range. Increasing the percentage of range resulted in increased average power, voltage, and current on low range; however, little increase in output was observed above $80 \%$ of range (Figure 2). Similar relationships were observed on high range. No interactions existed between boat and percentage of range. Average power output differed between the six 5.0 GPP electrofishing boats on low $(F=7.3$, df $=$ $5,28, P=0.0002)$ and high settings $(F=4.88$, df $=5,28, P=0.003)$. Boats B-2 and B-4 produced significantly higher power outputs at identical settings than did the other four 5.0 GPP boats (Figure 2).

\section{Model-7.5 GPP Electrofishers}

With a resistance of 25-26 $\Omega$, the maximum average power output of 7.5 GPP electrofishing boats on a $170-\mathrm{V}$ range was $350-360 \mathrm{~W}$, on a $340-$ $\mathrm{V}$ range was $1,361-1,383 \mathrm{~W}$, on a $500-\mathrm{V}$ range was $2,942-2,955 \mathrm{~W}$, and on a $1,000-\mathrm{V}$ range was 9,800-10,221 W. Under these conditions, the boats also produced $95 \mathrm{~V}$ and 3.7-3.8 $\mathrm{A}$ on the 170-V range, $187-188 \mathrm{~V}$ and $7.3-7.4 \mathrm{~A}$ on the $340-\mathrm{V}$ range, $274 \mathrm{~V}$ and $10.7-10.8 \mathrm{~A}$ on the 500-V range,
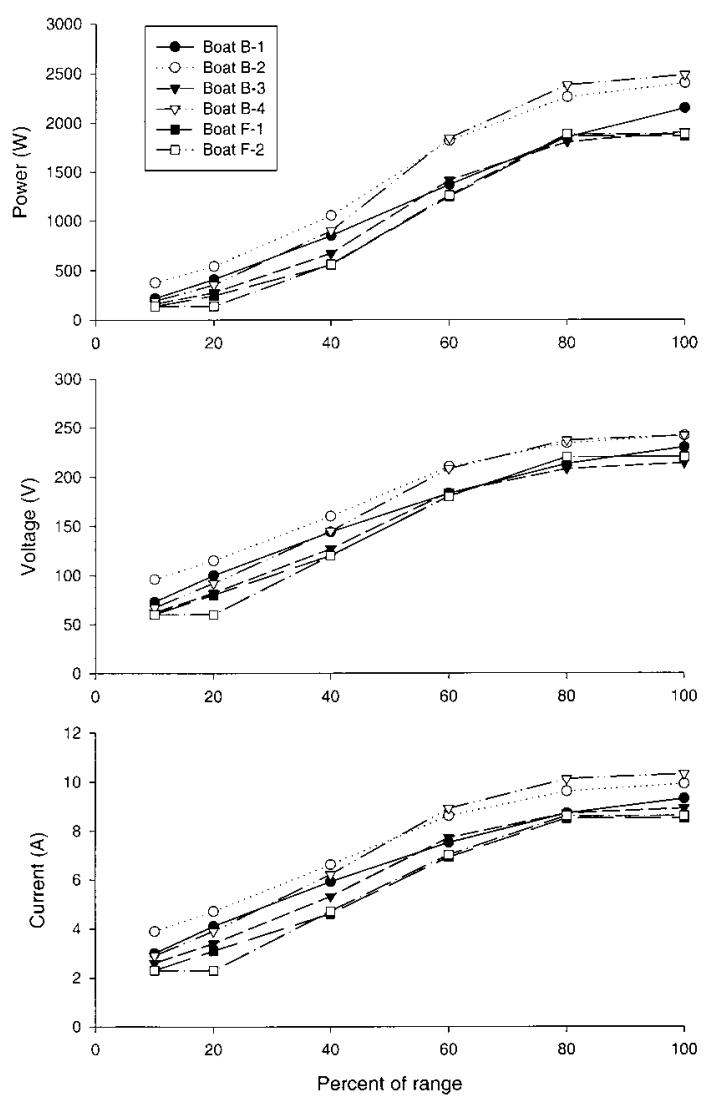

FIGURE 2.-Average power (upper panel), voltage (middle panel), and current (lower panel) outputs produced by six Smith-Root model-5.0 GPP electrofishing boats (squares $=$ factory rigged; circles and triangles = biologist rigged) with a resistance of 23-26 $\Omega$. Control units were set on low $(500-\mathrm{V})$ range and $60-\mathrm{Hz}$ pulsed DC.

and $495-505 \mathrm{~V}$ and $19.8-20.2 \mathrm{~A}$ on the $1,000-\mathrm{V}$ range. Increasing the percentage of range resulted in increased average power, voltage, and current on all ranges, similar to the pattern observed with 5.0 GPP electrofishers. Little increase in electrical outputs was observed above $80 \%$ of range. We did not perform statistical analyses on the 7.5 GPP electrofishing boats because of low sample size.

\section{Different Resistance Levels}

Increasing resistance (simulating reduced water conductivity) resulted in a nonlinear decrease in average power and current produced by both 5.0 and 7.5 GPP electrofishers (Figure 3). Voltage increased slightly as resistance increased. Furthermore, electrical waveforms from GPP electrofishers became smoother as resistance decreased. 

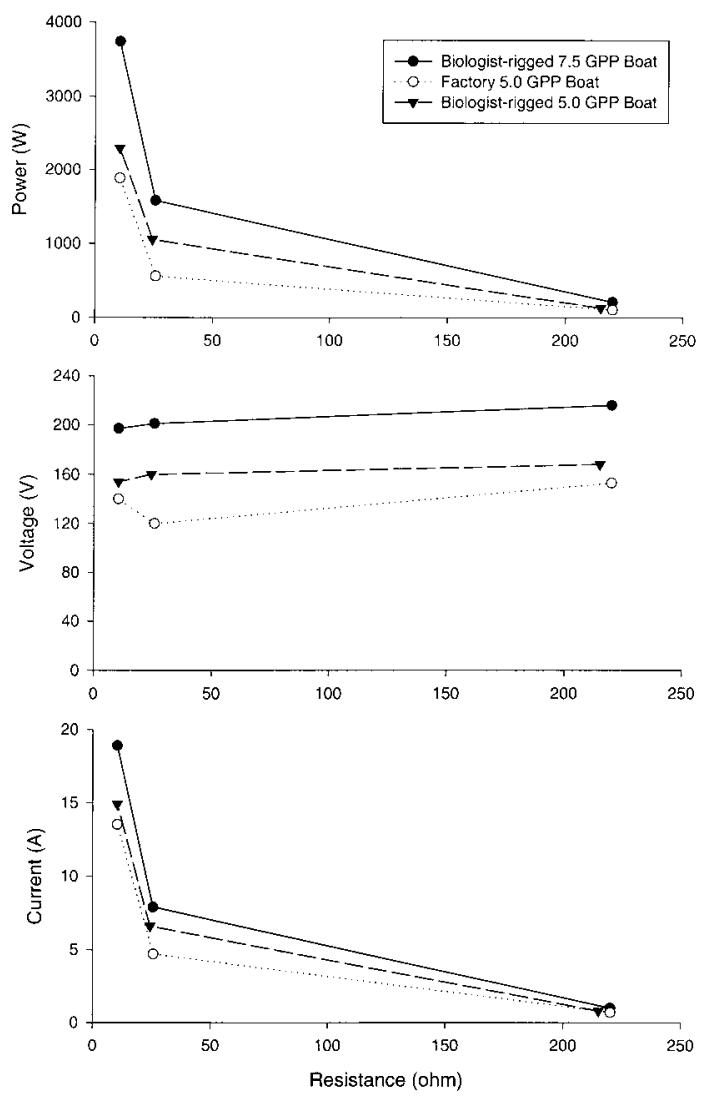

FiguRE 3.-Average power (upper panel), voltage (middle panel), and current (lower panel) outputs produced by a factory-rigged Smith-Root model-5.0 GPP electrofishing boat (open circle), a biologist-rigged model-5.0 GPP electrofishing boat (solid circle), and a biologist-rigged model-7.5 GPP electrofishing boat (triangle) using three $(10,24-26$, and 215-220 $\Omega$ ) resistances. Control units were set on $40 \%$ of the $500-\mathrm{V}$ range and $60-\mathrm{Hz}$ pulsed DC.

\section{Discussion}

Differences were found in average power outputs among the six variously rigged model-5.0 GPP electrofishing boats. Surprisingly, the biologist-rigged electrofishing boats with generators and control boxes purchased from Smith-Root were as or more effective than Smith-Root factoryrigged electrofishing boats in terms of power output. However, factory-rigged boats generally contained additional safety features that should be considered when purchasing electrofishing equipment. In addition, factory-built electrofishing boats may require fewer repairs. Benefits of additional safety features and reliability may outweigh the monetary savings realized with biologists-rigged electrofishing boats.
Differences in the 5.0 GPP electrofishing boats (e.g., wiring schemes, age of electrofishers and electronic accessories) had little effect on average power available to sample fish, probably because the resistance of these components was relatively small. As expected, the 7.5 GPP electrofishers were capable of producing more average power than the 5.0 GPP electrofishers because they had a more powerful generator. Furthermore, average power outputs for the two 7.5 GPP electrofishing boats were similar, providing additional evidence that setup differences (e.g., wiring and electronic devices) in boats had little effect on output. One potential age-related problem that we did not address is increased resistance due to deposition on the cathode (boat hull), which may eventually insulate the cathode from the water (Johnson et al. 1990). To correct this problem, biologists should remove deposits from boat hulls by sanding; doing so will help maintain the original efficiency of the electrofishing boat (James B. Reynolds, University of Alaska, Fairbanks, personal communication).

We were unable to calculate power output produced by the Smith-Root electrofishers using information obtained solely from control boxes (i.e., voltage and current). No voltmeter is provided on Smith-Root control boxes and the ammeter gives a relative, not exact, indication of current. Furthermore, a logistic relation (nonlinear) of voltage and percent of range was observed; thus, voltage could not be estimated by multiplying the range selected (e.g., $500 \mathrm{~V}$ ) by percentage of range. Given these limitations and the fact that boats produced different average power outputs with identical settings, additional electrical meters (e.g., voltage and current meters capable of measuring true root mean square values) would be needed to determine power output in the field and to standardize electrofishing efforts by power output. Alternatively, manufacturers should consider additional metering capabilities to aid biologists in monitoring and standardizing power outputs.

Changes in resistance (simulating changes in water conductivity) altered electrical outputs. An increase in resistance (a decrease in water conductivity) resulted in a decrease in average power and current, and a slight increase in voltage. Thus, standardizing electrofishing by power (as opposed to standardizing by voltage or current) among and within water bodies with different conductivities (as suggested by Burkhardt and Gutreuter 1995) will probably reduce the variance of catch rates and provide more appropriate comparisons of catch rates. Kolz (1989) demonstrated that the 
power transferred to a fish is related to the difference in conductivities of fish and water (i.e., maximum power transfer occurs when conductivities of fish and water are equal), Thus, different levels of power output are needed to elicit similar fish responses in different water conductivities. With the power transfer theory, a power correction factor is used to account for the mismatch between fish conductivity and water conductivity, whereby power output is adjusted to account for water conductivity. Thus, when the power correction factor is used to change the electrical field in terms of power, fish experience the same field (size and shape) at all levels of water conductivity (assuming that sufficient power is available to reach the level prescribed by the power correction factor). However, as noted earlier, the necessary information (i.e., output $\mathrm{V}$ and $\mathrm{A}$ ) to standardize power is not provided by the contemporary Smith-Root electrofishers.

We recommend that biologists record as much information as possible concerning electrofishing conditions (e.g., water temperature and conductivity, current type, voltage and current output, and calculated power output) so that future assessments and applications can adopt standard electrofishing conditions. Furthermore, few assessments have examined the amount of power output (and associated power density) needed to sample fish. Kolz and Reynolds (1989) found that a minimum power density of $100 \mu \mathrm{W} / \mathrm{cm}^{3}$ was needed to stun goldfish Carassius auratus, but little work has been conducted on other species. Therefore, additional assessments are needed for a variety of fishes to determine what power output and associated power correction factors are needed to sample fish with electrofishing.

\section{Acknowledgments}

We thank M. Parten for guidance in developing assessment procedures and interpretation of electrical theory. G. Wilde provided guidance with statistical assessments. L. Brezina, E. L. Buchanan, J. Hernandez, M. Howell, J. Ingle, and A. Wallace transported boats to Texas Tech University. T. Bonner, W. J. Dean, J. Dennis, S. Dumont, B. Farquhar, J. Findeisen, G. Jons, J. Kraai, R. Luebke, C. Munger, D. W. Novotny, R. Patiño, J. Reynolds, G. Wilde, and R. Zerr provided comments on earlier drafts of this manuscript. This is contribution T9-851 of the College of Agricultural Sciences and Natural Resources, Texas Tech University, Lubbock.

\section{References}

Burkhardt, B. W., and S. Gutreuter. 1995. Improving electrofishing catch consistency by standardizing power. North American Journal of Fisheries Management 15:375-381.

Johnson, I. K., W. R. C. Beaumont, and J. S. Welton. 1990. The use of electric fish screens in the Hampshire Test and Itchen, England. Pages 256-265 in I. G. Cowx, editor. Developments in electric fishing. Fishing News Books, Oxford, UK.

Kolz, A. L. 1989. A power transfer theory for electrofishing. U.S. Fish and Wildlife Service, Fish and Wildlife Technical Report 22:1-11.

Kolz, A. L., and J. B. Reynolds. 1989. Determination of power threshold response curves. U.S. Fish and Wildlife Service, Fish and Wildlife Technical Report 22:15-24.

Willis, D. W., and B. R. Murphy. 1996. Planning for sampling. Pages $1-15$ in B. R. Murphy and D. W. Willis, editors. Fisheries techniques, 2nd edition. American Fisheries Society, Bethesda, Maryland.

Van Zee, B. E., T. D. Hill, D. W. Willis, L. F. Brown, J. B. Reynolds, N. G. Sharber, and J. Sharber. 1996. Comment: clarification of the outputs from a Coffelt VVP-15 electrofisher. North American Journal of Fisheries Management 16:477-478. 